CAMBRIDGE UNIVERSITY APPEAL FUND.

$\mathrm{O}$ February 16, 1907, the late Duke of Devonshire, my predecessor in the Chancellorship of the University of Cambridge, was through your courtesy enabled to make a statement dealing with the needs of the University, and to give some account of the efforts made by the Cambridge University Association to obtain funds to increase the endowments of the University. The interest taken by him in the association and its work is well linown, and on succeeding to the Chancellorship I have accepted the invitation of the association to become its president. I therefore beg that you will now allow me to renew his appeal to all those interested in the promotion of higher education, learning, and research.

The fact that the majority of recent donors have been Cambridge men encourages me to hope that there may be many others amongst our graduates who will help us according to their ability. Others of our most munificent benefactors have not been themselves members of the University, and I would further appeal to all interested in the advancement of learning to enable the ancient University of Cambridge to continue the development of its sphere of usefulness. I believe that all acquainted with what has been done at Cambridge in recent years will agree that, to the extent of the resources available, progress has been satisfactory and in some departments remarkable.

In the letter which you published on February 21,1907 my predecessor estimated the needs of the University at nearly a million and a half. Since the financial position of the University was first made known, legacies for specific objects have been received to the amount of upwards of 100,000 . The late Vice-Chancellor in his valedictory address to the Senate gratefully acknowledged the continued liberality of the Goldsmiths' Company, as well as substantial donations from the Surveyors' Institute and the Clothworkers' Company. The munificence of the City Companies and the generosity of many private donors have thus enabled the association to transfer to the University sums amounting to about $\mathrm{x} 39,000 \mathrm{l}$. 'The Drapers' Company are giving roool. a year to the funds of the agricultural department. A further annual grant of $100 l$. for six years for economics is being given by the Girdlers' Company. Since the establishment of the association, the University has thus benefited to an amount of more than $250,000 l$.

A small committee of Cambridge men has recently been formed in London with the object of assisting the association in its efforts. The establishment of this committee was approved by the late Chancellor shortly before his death, and his nephew, the present Duke of Devonshire, has consented to act as its vice-chairman. This committe proposes to direct its attention to specific objects which may appear from time to time to be the most urgently in need of support. At the present moment the completion of the fund for building, equipping, and maintaining the laboratories of the school of agriculture is one such object, and we are indebted to the Duke for taking charge of this appeal, in which his uncle, the late Chancellor, had shown much interest. For this purpose 5000l. at least is still required.

It is not advisable to enter here into details as to the various directions in which further endowments of the University are urgently needed, but the Vice-Chancellor will be glad to furnish specific informatior. For the moment I will confine myself to indicating the projects which are engaging the immediate attention of the association and of the London committee. They are :-

(I) The completion of the fund for the school of agriculture.

(2) The completion of the fund for building the new museum of archæology and ethnology.

(3) The adequate endowment of modern languages.

With respect to this last requirement, I may explain that the mediæval and modern languages tripos, established in $r 884$, has recently been re-modelled on broader and more practical lines, and that it now includes English, French, German, Spanish, Italian, and Russian. The teaching in these languages is vigorously carried on. Readerships in the Romance and Teutonic languages exist; but there are in the University no professorships of French or German, or indeed of any other modern European language.

In conclusion, I beg leave to say that donations may be sent to me, or more conveniently, as I expect to be away from home for about six months, to Mr. E. H. Parker, the hon. treasurer of the Cambridge University Association, Barclay's Bank, Cambridge.

Teriing Place, Witham, Essex, October 5.

\section{THE IMPERIAL COLLEGE OF SCIENCE AND TECHNOLOGY.}

THE distribution of prizes and medals to students of the Imperial College of Science and Technology by Sir William White, K.C.B., on October 7 , may to some extent be regarded as the inaugural meeting of the college, since it was the first function of its kind at which the new rector, Dr. Henry T. Bovey, F.R.S., was present. In his remarks from the chair, Sir William White gave some particulars as to the work which has been accomplished by the governing body. He explained the objects of the new college, and said that a start has been made with existing institutions, but that branches of science and technology unrepresented in these institutions are to be added to the subjects in which instruction will be provided by the new college. Any higher instruction in technology which is provided in provincial institutions will, he said, be utilised, and every effort made to build up a great college capable of conferring advantages both upon the home country and the whole of the Empire. Referring to the appointment of the new rector, Sir William White remarked that in appointing Dr. Bovey the governing body has secured a man whose qualifications and experience represent in the happiest manner the imperial idea which will inspire the future work of the college. In conclusion, the chairman announced that it is hoped that in future years the honours gained by the students in each of the institutions included in the Imperial College will be presented at the same ceremony.

After the prizes and medals had been distributed the rector delivered his address, which is here published in full. At the conclusion of his address, Dr. Bovey announced the provision of the equipment of the mining and metallurgy laboratories in the new buildings, the plans of which have been prepared by Sir Aston Webb, and the erection of which will be begun in the near future; the gift by $\mathrm{Mr}$. Charles Hawksley of $4000 l$. for the equipment and endowment of an hydraulic laboratory in memory of his father; the equipment and endowment of electrical engineering laboratories at the college in memory of Lord Kelvin-a project which has met with the hearty approval of the King; and many valuable donations for the college library and museum. A vote of thanks to the rector for his inspiring address was proposed by Sir Norman Lockyer, K.C.B., who insisted that in all higher instruction in science and technology the great requisite is quality rather than quantity of work, and that the duty of an imperial college is not only the production of the skilled technologist but of men in the best sense of the term fully able to take their share in the work of the Empire.

\section{Rectorial Address by Dr. Henry Bovey, F.R.S.}

We are met to-day as a section of the Imperial College of Science and Technology, a union of longestablished and justly famed institutions. We are looking forward to a career the usefulness of which shall combine that of each of our component parts, and which will give to London another channel in which its force may be expressed as a whole. This is no light undertaking, and it would seem that the most appropriate subject on which I can speak to you to-day is that of our aims and ideals in this union, together with any suggestions which may occur to me as to the best means of carrying them out; and it may be well at the outset of our career, so to speak, if we should spend a few minutes in considering the advantages and disadvantages which are inseparable from our constitution.

I cannot doubt that in the Imperial College we shall

No. 2033, VOL. 78] 
find ourselves confronted with the same sort of problems as have beset other unions of all degrees of complexity, from family life to a United Germany or a United States -the problems, namely, which arise from the new mutual relations of the parts. In my opinion there is nothing to be gained and much to be lost if we do not frankly face these problems and see-yes, and foresee, so far as possible -the limitations, the responsibilities, the foundations, and perhaps the dangers of union.

In these days we do not need to be persuaded that union is strength, for it may be called the panacea of the age, and men fly to it as their only method of accomplishing every kind of object; but we do not so clearly see that a union is not necessarily strong in direct proportion to its numbers. The bridge-builder should not need to be reminded that there is a point beyond which length becomes a danger, yet we find in practice that there is still a temptation to make an engineering work the largest in the world-a temptation, in fact, to measure greatness by size. That we may be less likely to fall into this error, let us set before ourselves some ideals as to the quality of our union. I shall be forgiven, I am sure, if I seem to speak of the old and the obvious.

In any union of equals, if the members are to be loyal to the idea which has brought them together, they must remember that it is possible for selfishness to entrench itself in the care of one's particular and special department and in the ambition for its paramount influence, and that in this case, as in individual instances, he finds himself best who loses himself. This last resort of selfishness, as we may call it, not infrequently becomes apparent when there is a question of unequal advance. It is not unnatural that in such a case there should be a lurking sense of injustice, particularly if, as often happens, the new privileges fall to the share of the new departments and leave the old apparently unrecognised. The elder brother is not extinct even in the twentieth century. Yet, viewing the matter more largely, not only is it absolutely true that an increased advantage to, or an increased demand for, any special part increases the value and reputation of the whole, and therefore of all other parts, but if we think of it this is the usual method of growth in institutions which are not altogether the creation of Aladdin's lamp. Usually there is not enough of money to go all round at once, and we must be content if it goes around in time. In parenthesis, let it be taken for granted that it will be someone's duty to see that the time is not too long deferred.

Next, may I remind you that in a union of equals responsibility falls equally on all? How often do we hear it said, "I cannot help it, they would do it!" How often does a man rest content with not being an obstructionist, and never reflect that there is an active duty required from each person if the general good is to be achieved. What right has a man to sit down and let another do his share? It may be quite as bad to be indifferent as to be too anxious to lead. As to being an obstructionist, that is to put oneself outside the pale altogether-for it is to be a positive source of disunion. In order to secure wisdom as well as energy in the taking of personal responsibility, it will be well to think of the real foundations of union, which, for our present purpose, I may briefly put as :-first, a common object; second, a common method of obtaining it; third, a spirit of mutual respect and good-will.

The first and second will require in this instance a morc lengthened discussion; the third we can count on in a convocation of educated and right-minded men, yet as the association is so close and the possibilities of clashing so many, it is well to keep it in mind as an essential.

Two dangers only I shall mention, opposite tendencies which, not seldom, are the fruitful sources of much evil. The first is the evil of courting popularity-of waiting to see which way popular opinion may lean. About this manv things might be said which there is no time to say, but in general we may perhaps assume that the evil lies in shaping our course with any reference to the security of our own position, either in fact or in the esteem of others.

Then there is the reverse danger of being always in the opposition. It seems unlikelv that every man who finds himself solitary should be an Elijah, and if he is like Elijah he should teach himself to recognise the 7000 likeminded.

Let us now consider a few suggestions as to our common object in the Imperial College and the best method of attaining to it. First, then, as to our object.

It may be well to think a little of our title as expressing our aims. Why do we separate science and technology in the title of this institution? Does it come from some feeling that technology is different from science, or that it is science plus something else? Some time ago I had occasion to study the relations of science and technology, and came to certain conclusions, which I may be allowed to give you without entering into the discussion of them.

Perhaps the most clear and concise definition I have come across of pure science is that it is "the knowledge of powers, causes, or laws considered apart or as pure from all applications." It involves the making of experiments, by which these laws have been made manifest. Compare this with the will of Count Rumford concerning the founding of a chair at Harvard in 1816 for teaching " the utility of the physical and mathematical sciences for the improvement of the useful arts." If we examine the curricula of the best modern schools of technology, we find advance has been made in this conception, and that they include :-

First, a study of selected laws of nature (i.e. those which have been or may be applied to practical purposes) $(a)$ as seen in nature; $(b)$ as seen in examples or descriptions of the means by which they have been utilised. This includes the study of all types of machinery, implements, and instruments.

Secondly, a distinct aim to train the mind of the student so as to develop what may be called the scientific mind; as yet this has been mainly attempted only by causing the student to study in a scientific manner.

Thirdly, (a) a research into the nature of the practical facts essential to any art with the view of finding out the known laws of nature on which they depend; $(b)$ orioginal research into the problems arising out of industrial processes with the view of finding out unknown laws of nature, and especially those which must be investigated on a large scale.

We see that technclogy, while in one department a pure science, investigating any problems arising out of the artificial working up of natural products, is in the main to be called an applied science--that its applications, even when exactly similar in outward appearance to the experiments called for by pure science, differ from the latter in one important particular. In the case of pure science the resulting fact is viewed as an instance of a law; in the case of technology, the fact itself. is the important thing. Therefore the idea of utility seems to be the real key to the difference between the two-which seems to be a difference of aim. If our purpose is to establish a law we call it pure science; if our purpose is to establish a fact we call it applied science or technology.

Having thus more or less defined the difference between the two, we may say that our common object in the Imperial College is to give the right education in science and technology, and if we agree with the conclusions I have quoted we shall see that there should be great economy in combining the training in these two, the foundations being, in both cases, practically similar, and the only real difference coming from a wish to specialise either on the theoretical or on the practical side in one's professional life.

We may take it, in fact, that there will be less waste in the world's advance if the scientific man is influenced in his choice of his research by practical necessities, and if the practical man is influenced by pure science so as to be interested in and to recognise the light which may be shed on scientific relations by accidental or intentional changes of circumstances in the course of his work. There is no necessity in the nature of things that pure science should be absolutely lost in applied science. An education in the same place and under the same influences should therefore be desirable as givino opportunities for the increase of mutual knowledge and respect.

Our common object might be now a little more fully stated as the attempt to develop the ideal scientific and 
technical man. It is evident that the clearer our conception of what we want to produce, the more likely we are to attain to it. In reading and trying to harmonise the various ideals which have been brought before our notice by many distinguished writers and speakers, we are forced to the conclusion that no mere specialist can possibly fulfil modern requirements. Looking backward, we can see that formerly the scholar and the man of action were separated in idea and generally in fact. We can realise the change that has taken place, and can perceive that the ideally educated man of the world of to-day must possess, not only powers of thinking, but powers of doing. and must show that he has the will to do honest work both with and for his fellows.

One case occurs to me as confirmatory of this position as regards the mere specialist - the case of a man extremely successful in a line of life not originally chosen. Our hasty conclusion is usually that his first choice was bad, and bound to end in failure; but another quite possible explanation is that he does well in his second choice, just because, having possessed another point of view, he is more quick to grasp the possibility of those combinations which have characterised much of the advance in modern science.

I fancy there will be little disagreement as to the kind of man we want to produce, but when it comes to agreement on right methods we cannot hope to find unanimity of opinion. All we can expect to attain is a working hypothesis, and trust for the rest, first, to what is really the greatest factor in all true education, namely, the personality of the teacher, and next, and scarcely less, to the attitude of the student. Still, a working hypothesis must be embodied in every curriculum, and, to be really valuable, must be fixed enough to conform to the eternal laws of the mind and elastic enough to admit of constant translation into what we might call the scientific language of the moment.

Now that scientific training has acquired a foothold which justifies the existence of all the scientific and technical schools of the world, and the establishment here of a college such as we are contemplating, it can afford to spend a little time in adjusting its methods and examining its results.

What, then, is the general tendency of tnat which has been called a practical education in either science or technology, namely, an education intended to prepare a man for his life's work by direct methods only, as, for example, if we should try to train a man to be a mining engineer by giving instruction solely on those points which would be of immediate commercial value to him? I think, in comparing results, we must conclude that an education in facts, and even in laws and processes alone, cannot produce what we call the scientific mind. If we are to select the powers of the mind which are most essential to the scientific man, we shall find these generally admitted to be observation, concentration, imagination, the logical faculty, and last, but not least, the power of doing. No matter, then, how good an education may be, if these are not well developed it must be incomplete, and as the scientific man is, after all, first a man and then a man of science, nothing which leaves out of sight his intellectual relations with his fellow-men of this and other generations, nay, further nothing which leaves out of sight his obligation to rule his life in accordance with the highest standards of health, of religion, and of morals, can fairly be called a good education. Viewed from this standpoint, the task set before itself by the Imperial College is by no means simple, but I think much may be done by throwing cmphasis on processes rather than, or perhaps as well as, on results. It may be possible to give credit for evidence of the use of the powers that we seek to produce. For example, let us enter into some detail and see what this would involve. One would think, from most of what has been written on the subject of observation, that the power to observe, which does really seem to follow the system of training by experiment, was a power which, once grained, would necessarily be exerted in any direction; but, as a matter of fact, do we always find that a botanist, trained to observe, amongst other things, the colours of nowers. will always observe the colours, say, of ladies' dicesses? Do we find that a geologist, who recognises No. 2033 , vor. 78 ] every stone in his path, will always and at once recognise different types of men? It is interesting to note, in this connection, an experiment published in a recent book, from which it appeared that evidence taken from a large number of scientifically trained men showed a considerable number of cases in which important and even typical details were omitted.

Again, there the diffusiveness caused by the observation of unnecessary detail, which ougint to be corrected by what is almost equally necessary to the student-the power of selection which is implied in concentration. No one needs to be persuaded of the value of the logical faculty, but we may remark that, although it cannot but be trained by the study of mathematical problems, yet that in the solution of the problems of life it is very possible to find that personal bias is so strong as to prevent its exercise.

From these premises we might reasonably argue that more attention should be paid to the application, in different directions, of the observing powers and of the reason. Further, I believe we should do well to admit more generally than we do that in the higher walks of science the reason must often be preceded and supplemented by what we must regard as even a loftier faculty, inasmuch as when present in a high degree it amounts to geniusI mean the imagination. I should like to insist a little on this, because of its great importance. Whether from the belief entertained by many that the imagination is not required on the scientific side of education, or from overhaste in education, which is the very natural result of an age of nervous over-pressure, I cannot tell, but the result has been that little provision has been made for its exercise in purely scientific schools-this in spite of the fact that it seems to be a natural concomitant to training by experiment on account of its close relation to visual memory.

The imagination could be made of the greatest service in the proper study of science, and would, if rightly used, prevent much of the cramming, against which we are all setting our faces. It should then be possible to train it, even by the study of science; but a more rapid stimulus would probably be found in the reading of good literature, history, poetry, and the study of art in any form-subjects often received by science students with a feeling akin to contempt, as being unworthy the serious attention of a really practical man.

Yet the search for ideal truth, like the search for ideal beauty, requires the imagination as its instrument, and to leave out one of the most important means to the end we wish to reach is clearly not science; therefore, I say, let us cultivate the imagination, and if the introduction of other subjects into a scientific course is really the quickest way to that end, let us introduce them into the training, but let us devise means to prevent their becoming merely a fresh tax upon the students' time. As a matter of practical politics this may be ensured. I believe, by studying them, not with the view of acquiring knowledge, but strictly with the view of acquiring a power.

We have said that the scientific man should be a man of practical capacity, the man who can $d o$, and, if possible, the man who can make-powers which do not always go together. Generally speaking, our schools of science succeed in training the latter, but very little importance seems to have been attached to the necessity of giving any training in the former. Nor does it appear to be safe to leave it to instinct, as the not uncommon proceeding of students, viz. to dawdle through a term and cram at the end, is the very last manner in which it would be desirable to "put through work" in after life. The power of dealing with men in every relation of life and of learning, to some extent, the responsibilities of citizenship should be provided for in a reasonable degree by encouraging social intercourse, by the promotion of clubs for mutual improvement and recreation, especially those for the discussion of the problems of the day. In such ways the student may learn to handle affairs both of business and of citizenship.

Of course we cannot make bricks without straw, and we must recognise that if all this is to be done, or even aimed at, it will take time to do it, which brings me to the general subject of over-pressure, a burning question in these days, when by perpetual competition, from the very earliest years, we risk spoiling our best intellects in the endeavour to quicken the sluggish current of our duller 
minds. The standard of quantity in learning, like the price of food, seems to be perpetually rising, and as the human mind shows no very lively signs of expanding in direct proportion, but, on the contrary, shows some tendency to collapse, it would seem to be well to think more of quality in work and less of quantity. We must remember that forced growth in plant or man is in the end destructive. The day of the grammarian, celebrated by the poet, is perhaps gone, and it is more than doubtful if we want to read his whole book; but we should do well to take at least a page out of it, and allow our ideals to be, not shaped, but modified by the splendid sentiment, "Leave now for dogs and apes, man has forever."

If, then, we could plan our curriculum with more provision for this training of the powers, as apart from actual professional work, and with at least a tacit recognition of the fact that rest and recreation must follow mental exertion, and precede more exertion if that "more" is to be effective, I think it would be possible to require a much higher quality of work and make up for omissions in detail of direct training, which, after all, if one knows how, can be learned in the first stages of practice which follow college life. This little phrase, "if one knows how," should really indicate the difference between the man who enters shops direct and the man who enters them after college work. Our results in practical work should, if we are on the right track, prove, what is not questioned any longer in many places, that the college graduate is the man who is wanted in business life.

As to those higher elements of character, without which no education is of much avail, in these especially the training must be indirect, but never neglected. In every college there are endless opportunities for self-knowledge, self-control, and, if a man so choose, for self-sacrifice. In a scientific college there are special influences making for the development of character. The constant effort to eliminate error tends towards the development of truth and accuracy. The cultivation of the will in overcoming obstacles should produce the sturdier manly virtues; the patient waiting on nature's working encourages the gaining of a wise self-restraint, which we may hope to see employed in the directing of life; and the emphasis laid on the pursuit of truth for its own sake should help to overcome the spirit of commercialism-that caring for scientific success mainly for what it will bring in financial success-which is an ever-present danger of the application of science to life.

We see then, in general, that we should like to make it our aim in the Imperial College to develop scientific education both on the imaginative and on the practical side by, on the one hand, bringing our men into somewhat closer touch with the noblest thoughts of the past and with the world-wide strivings after truth which characterise our present age; on the other hand, by inviting the advice and cooperation of men of business and of professional men in actual practice, so as to keep our courses in accord with their methods, and, if possible, to earn the reputation of being the place where an employer must easily find the man he requires.

Finally, we consider that if we can succeed in training men to be at once good scientific men and good citizens, we shall have done the best that is possible to serve our country by giving to it a class of workers who can be trusted to put the true service of man above their personal success, who are willing patiently to search for truth in hidden and dangerous places, who will be able to follow true laws of economy, and to prevent some of that waste which we now see going on in painful contrast to the destitution which runs parallel with it. Such men often show a capacity for leadership through individual force of character, and are no less ready to follow with unselfish devotion the path of common duty.

With grateful pride we may say that, to a high degree, these things have been already achieved by the associates of the several institutions now uniting in the Imperial College. We recall the eagerness with which some of our students went to serve their country in South Africa. A tablet has recently been set up in the Royal College of Science to keep their memory before us. We believe that of very many, had they found a chronicler similar things might have been written as were actually penned by a No. 2033, VOL. 78] western poet about one of the Associates of the School of Mines :-

\author{
Say judging as best they can \\ That in lands which try mannood hardest \\ He was tested and proved a man.
}

In conclusion, I am permitted to make some very pleasant announcements. The Bessemer committee has provided, as most of you are aware, for the equipment of the mining and metallurgical laboratories in the new building, of which the first plans have already been prepared by Sir Aston Webb, and the erection of which is to be commenced in the near future.

Again, a gentleman [Mr. C. Hawksley], who I am glad to see is with us to-day has very generously consented to equip and endow a hydraulic laboratory, which, we hope and believe, will render it possible to investigate many problems of flow which have not heretofore been attempted.

I am sure, too, that it will be no small satisfaction to all those present that, with His Majesty the King's hearty approval, steps are being taken to equip and endow certain other important laboratories.

Many and valuable donations, too numerous to mention in detail, have also been received from Canada and the United States, for which we are most grateful.

Lastly, the roll of honour of those who have occupied the chairs in the different sections of the Imperial College is a very long one, and includes many names which have made England famous in the world of science. I cannot but think that many would like to have a permanent mernorial to the names of such men in the form of chairs, laboratories, scholarships, or library endowments. In this matter of giving I should especially wish to enlist the sympathy of the Associates who leave these halls year after year. None have contributed more to the success and advancement of the universities of America than their own graduates. Every college of importance has an alumni association. The class sent out each year appoints its own secretary, who is expected to keep in touch with all its members, each of whom contributes a small sum annually to a special fund intended to help his alma mater. Most excellent has been the result of the scheme. Thus, at one of the great universities, a sum of 10,000 . is annually given for general purposes, while a large reserve is always available for any special need. A further advantage is found in the fact that the alumni are always kept in close touch with their college, are imbued with a real esprit de corps, and consider it not only a duty but a pleasure to help the institution which has prepared them for their life's work.

There is a grand opportunity for benefactions in the Imperial College if progress is to be maintained and if, as we hope and expect, we are to become the central, the Imperial Scientific School, imperial in conception, imperial in our sphere of work.

\section{GEOGRAPHY AT THE BRITISH ASSOCIATION.}

THE geographical section of the British Association this year was particularly fortunate in the meeting place allotted to it, for better accommodation could not be desired than that afforded by the theatre in the Royal Dublin Society's building in Kildare Street.

Opening the sectional meeting on Thursday, September 3 , the president, Major E. H. Hills, took as his subject the survey of the British Empire. His address amounted to a plea for the more thorough organisation of the Imperial survey, and he dealt with the work, not only retrospectively, but prospectively, analysing present methods, discussing their shortcomings where such exist, and suggesting plans for the future. One of his most notable recommendations was that the re-measurement of the two principal arcs, meridional and longitudinal, should be undertaken by the British Ordnance Survey, and this recommendation was afterwards embodied in a resolution forwarded by the sectional committee to the council of the association, suggesting that the Board of Agriculture and Fisheries (which controls the Ordnance Survey department) should be memorialised to this effect, and the committee 